\title{
Apptastic!
}

\section{Valuable Legal and Productivity Apps for Attorneys}

\author{
Thomas "TJ" Striepe
}

Alexander Campbell King Law Library

University of Georgia School of Law

Athens, GA 


\section{Table of Contents}

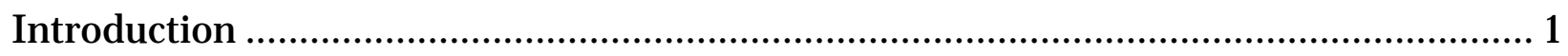

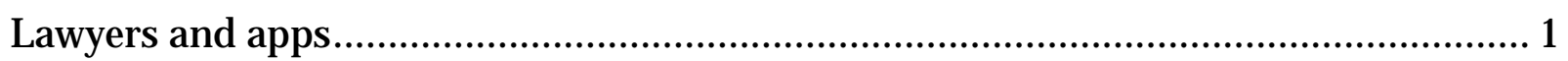

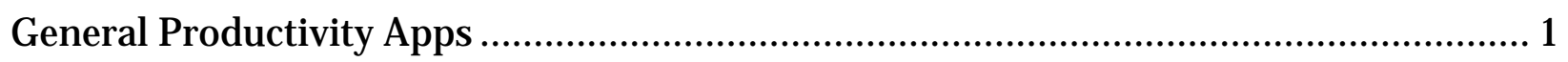

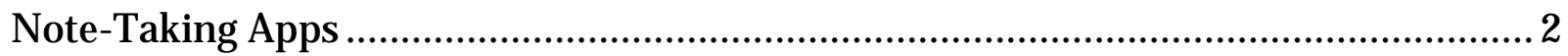

Penultimate [Free - iOS] .................................................................................. 2

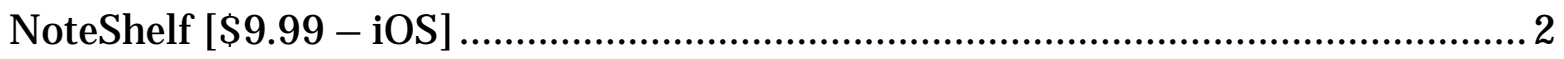

OneNote [Free - iOS, Android, Windows Phone] .......................................................... 3

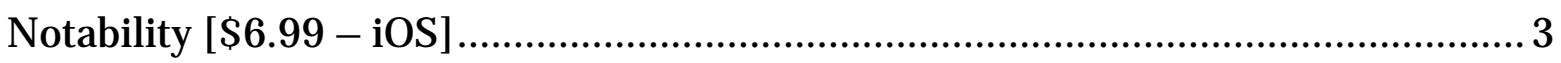

Evernote [Free - iOS, Android, Windows Phone] ........................................................ 3

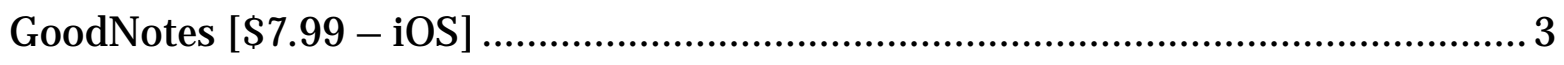

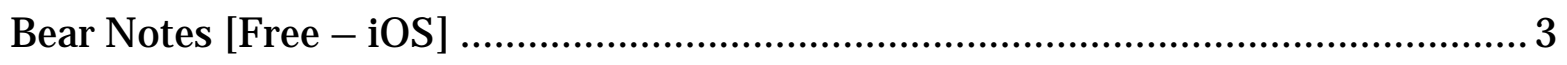

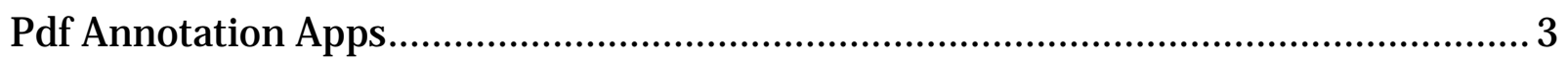

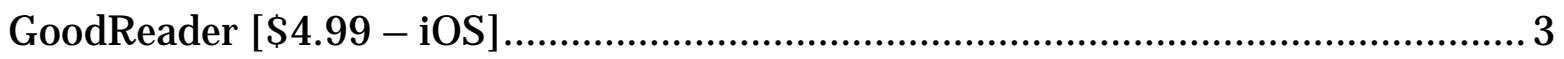

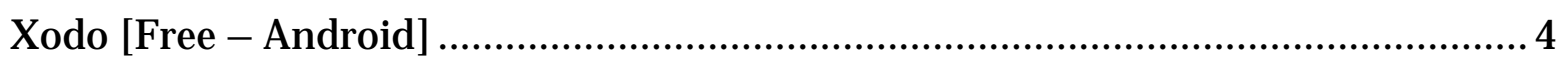

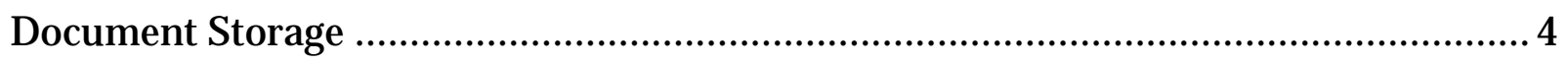

DropBox and Box [Free - iOS, Android, Windows Phone]......................................... 4

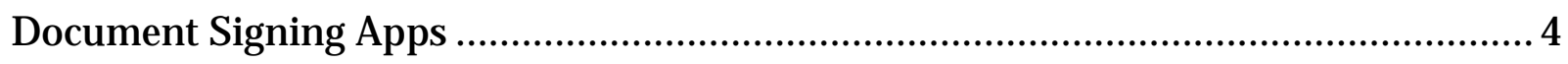

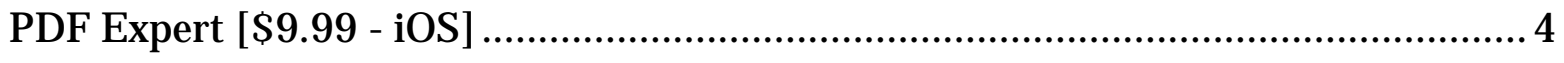

Other Essential Productivity Apps ................................................................................ 4

Documents to Go [Free - iOS, Android, Blackberry] .................................................. 4

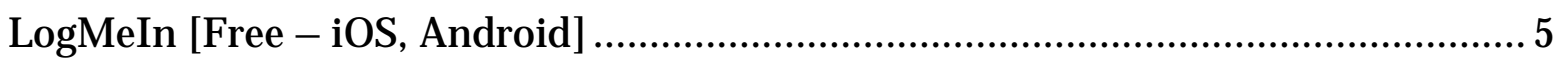

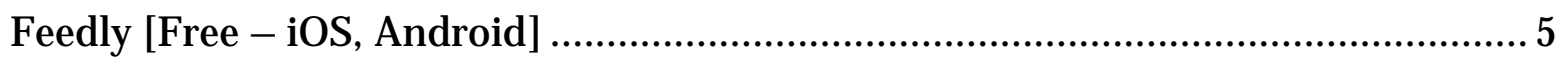

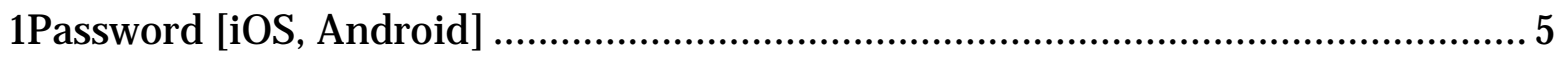

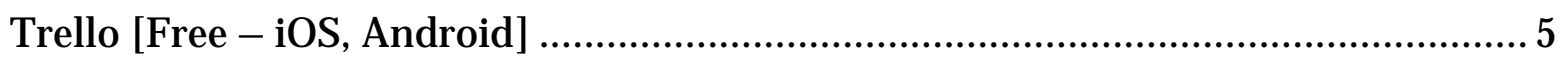




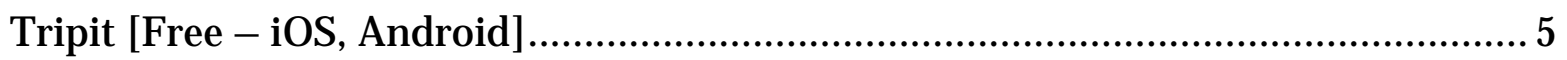

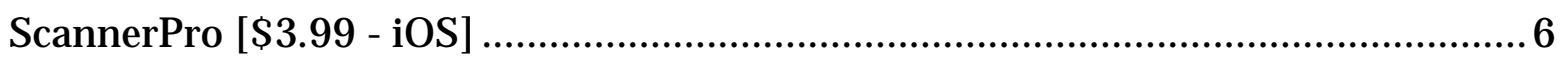

Dictate + Connect [Free Version, \$16.99 iOS; \$9.99 Android] ................................... 6

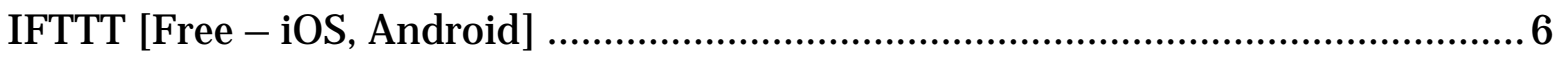

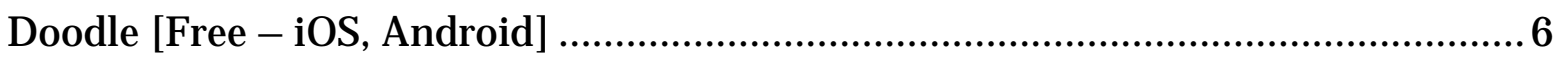

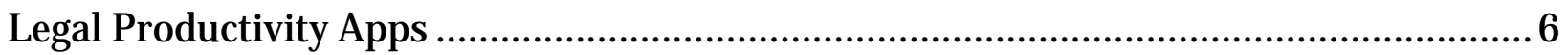

Courtroom Apps........................................................................................................ 7

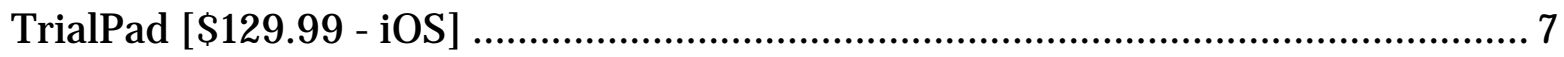

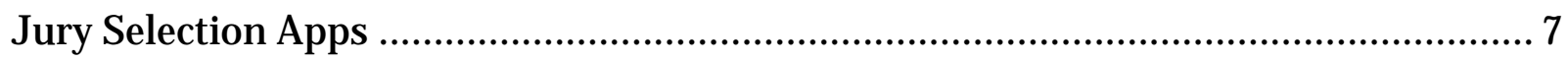

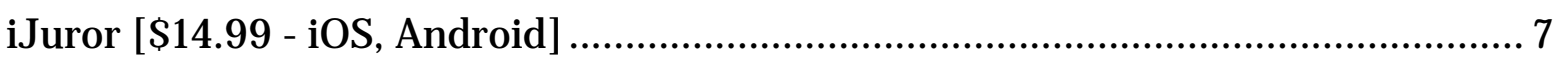

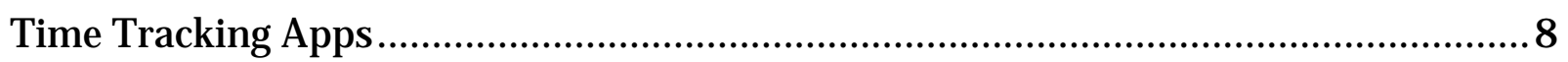

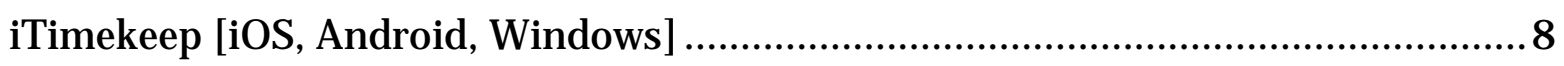

Time Master+Billing [ $\$ 9.99$ - iOS, Android] ........................................................... 8

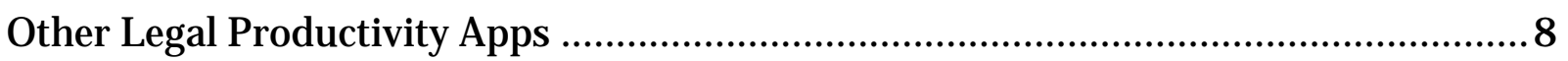

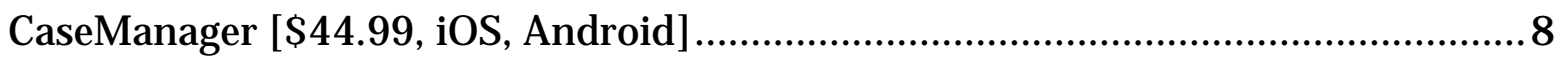

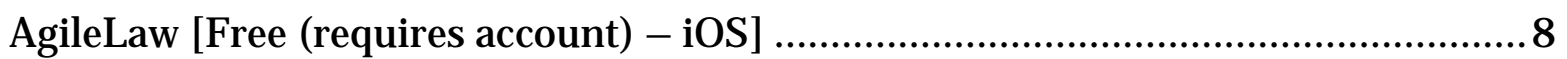

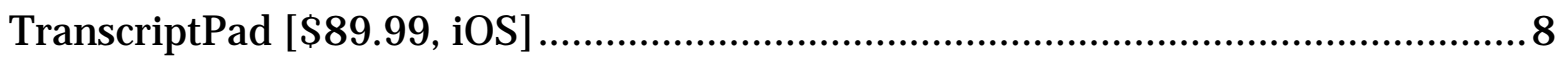

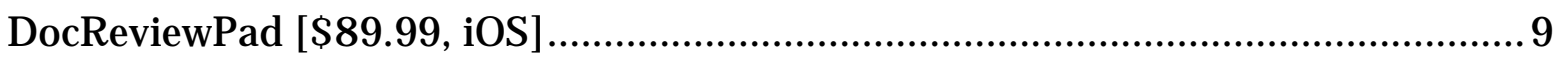

Cite-Checker [\$2.99 - iOS, Android] ...................................................................... 9

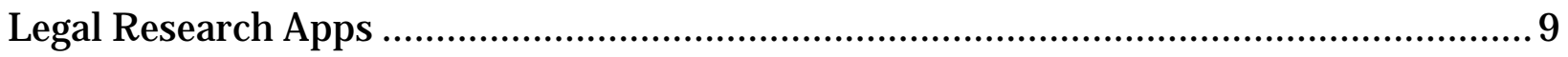

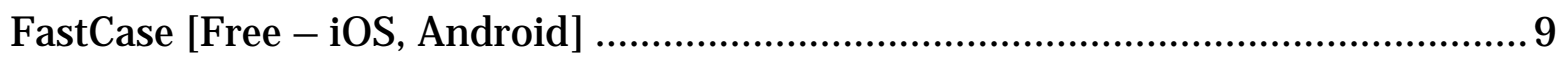

Westlaw [Free (for subscribers) - iOS, Android] ........................................................ 9

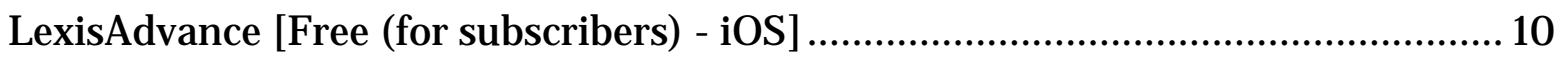

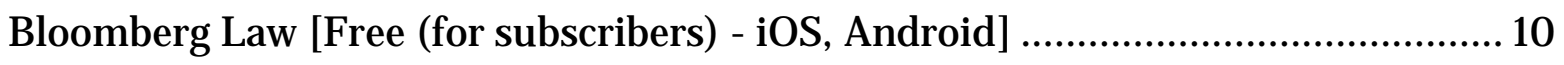

HeinOnline [Free (for subscribers), iOS, Android] .................................................... 10 


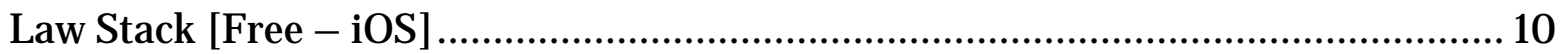

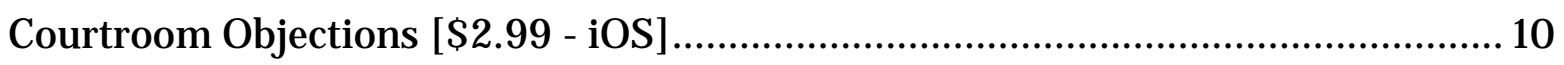

Wolfram Lawyer's Professional Assistant [\$4.99 - iOS] ............................................. 10

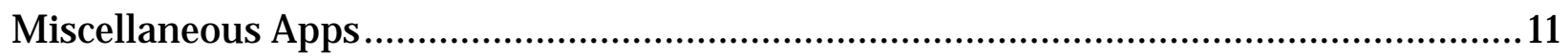

FindmyiPhone [Free - iOS]; Android Device Manager [Free - Android] ......................11

Crackle [Free - iOS, Android] ..................................................................................... 11

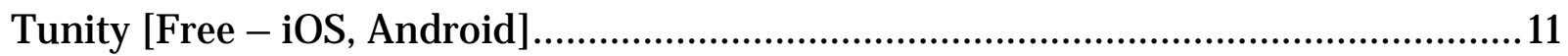

NPR One [Free - iOS, Android] .................................................................................. 11

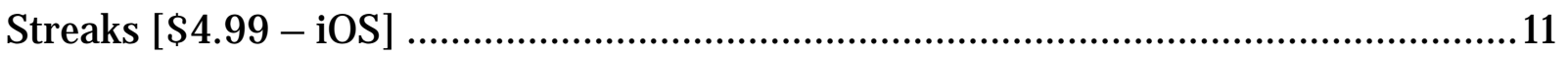

Whitenoise [Free - iOS, Android] ............................................................................. 11 


\section{Introduction}

\section{Lawyers and apps}

Lawyers' use of smartphones continues to increase. According to the ABA's 2017 Legal Technology Survey, 95.6\% of lawyers use a smartphone. Of those lawyers who are using smartphones $74.9 \%$ preferred the iPhone, 21.6\% used an Android based phone and the rest of smartphone users owned a Blackberry or Windows based phone.

Lawyer's use of tablets has stabilized. It actually decreased to $49.8 \%$ in 2017 from 50.6\% in 2016. There was a large increase between 2012 (33\%) and 2013 (48\%), however, it now seems that the increase in use of tablets is flattening out. Most attorneys (81.3\%) are using an iPad. For attorneys not using an iPad, 9.9\% use an Android device and 11.1\% are using the Windows surface (note - the percentages total over 100\% because some attorneys use more than one device).

Most attorneys are only using the default apps available on their smartphone for work (i.e. mail, calendar, notes and reminders). According to the 2017 technology survey, only 53\% of attorneys have downloaded a non-default app for their work. However, many apps can assist attorneys in being more productive. There are apps to assist lawyers in tracking time, performing legal research, editing documents, and coding a deposition. This paper will introduce attorneys to some apps to make you more productive and effective in their work.

\section{General Productivity Apps}

Even though these apps are not designed specifically with attorneys in mind, they will provide you with tools to allow your smartphone or tablet to be more effective. The apps below will let you take notes, annotate documents, and improve your ability to perform work on your mobile device.

While lawyers continued to download legal-specific apps like Westlaw, LexisAdvance, TrialPad and TranscriptPad, they also downloaded general productivity 
apps. Here are the most popular general productivity apps downloaded by attorneys during 2017, most of these will be discussed below:

1. Dropbox

2. LinkedIn

3. Evernote

4. GoodReader

5. LogMeIn

6. Docs to Go

7. Box

8. Quick Office

9. MS Office

10. Notability

\section{Note-Taking Apps}

There are some note taking apps that are simply like notebooks and there are others that provide a number of features. I will describe a few of the more popular ones below, but I suggest first downloading the free versions of these apps to determine which ones work best for your needs.

\section{Penultimate [Free - iOS]}

This app allows you to transform your smartphone or tablet into a notebook using a stylus. This app was developed by the makers of Evernote so it has a very good reputation. After you have taken your notes, you can then organize them within notebooks. After your notes are organized, they are fully searchable and can be shared with your colleagues. Squid is a similar alternative for Android users.

\section{NoteShelf [\$9.99 - iOS]}

This app allows users to take notes, record audio, draw perfect shapes and annotate pdf's. This app also allows individuals to sign documents. You can use this app with your finger but it works better with a stylus. 


\section{OneNote [Free - iOS, Android, Windows Phone]}

This note-taking app allows you to take notes, clip web pages, and capture photos. The biggest advantage of this app over other note taking apps is that it has full integration with Microsoft Office.

\section{Notability [\$6.99 - iOS]}

Even though this app is not free, its features make it worthwhile. It has all of the features of the free note-taking apps (type or write notes, clip videos and photos, and organize them), but it also lets you annotate pdf's. One of the great features of this app is the ability to sync your written notes with an audio recording. If you are recording a presentation or other matter, you can tap a word or picture to see what the individual said at that moment. LectureNotes is a similar alternative for Android users (\$4.49).

\section{Evernote [Free - iOS, Android, Windows Phone]}

Evernote is one of the most popular note-taking apps for good reason. Not only does it allowyou to take notes, it allows you to collect articles, photos, and other documents; then organize them. The app features text identification that can recognize handwritten and printed text.

\section{GoodNotes [\$7.99 - iOS]}

GoodNotes is one of the most popular and best-reviewed note-taking apps. This app lets you easily take handwritten notes and annotate pdf's. Your documents in GoodNotes will synchronize between your iPad and iPhone automatically.

\section{Bear Notes [Free - iOS]}

A popular new app for note taking. Bear works on all Apple devices and continuously syncs. It is very easy to use and has some great editing functions.

\section{Pdf Annotation Apps}

\section{GoodReader [\$4.99 - iOS]}

This app not only lets you annotate pdf pages, it also supports Microsoft Office documents, HTML pages, audio and video. The new features allowyou to add, delete and rearrange pdf pages. This app will sync up with DropBox and OneDrive and has an 
outstanding interface. iAnnoate [\$9.99] is also a another great alternative for pdf annotation with Apple devices.

\section{Xodo [Free - Android]}

This app is a solid pdf reader and editor for Android devices. This app allows you to read, annotate, sign and share pdf's while syncing with Google Drive and Dropbox. This app has consistently been rated as one of the top pdf annotators for Android devices.

\section{Document Storage}

\section{DropBox and Box [Free - iOS, Android, Windows Phone]}

These apps allowyou to upload documents to the cloud and retrieve them from anywhere. They both have similar functions and have free versions for a certain amount of storage. These apps allow you to upload a document on your tablet and then retrieve it from your home computer or phone or share it with others.

\section{Document Signing Apps}

\section{PDF Expert [\$9.99 - iOS]}

This app lets users edit, annotate and sign pdf documents. Instead of printing, signing, scanning and sending a document back, you can simply sign it on your mobile device. Adobe Fill \& Sign is an inexpensive alternative and is available for Android users as well.

If you are looking for more advanced electronic signature apps/software Adobe EchoSign, Docusign, Cudasign and RightSignature all provide good solutions.

\section{Other Essential Productivity Apps}

\section{Documents to Go [Free - iOS, Android, Blackberry]}

This app lets users view, edit and create Microsoft Word, Excel \&PowerPoint files on both Apple and Android devices. This app also includes a desktop application, for both Windows and Apple computers, so that you can synchronize between your office computer and your mobile device. There is also a version that supports Google Docs, Box, Dropbox, iDisk and SugarSync. 


\section{LogMeIn [Free - iOS, Android]}

This app allows you to remotely access your PC's and Mac's from your smartphone or tablet. This way you can control your home/ office computer from anywhere. This app also has premium versions that allow you to sync files with your desktop computer, include printing features and options for multiple users.

\section{Feedly [Free - iOS, Android]}

Everyone has their favorite blogs they follow. Whether it is for legal, business or world news; entertainment; or updates on your favorite sports team, this app does an excellent job of keeping you current. Feedly allows you to organize all of your favorite blogs at one spot. Simply download this app and then subscribe to the RSS feed from your preferred blogs. Feedly also integrates with Facebook, Twitter, Evernote, Buffer, OneNote, Pinterest, LinkedIn and others.

\section{Password [iOS, Android]}

It is dangerous to use one password for all of your secure accounts, but it is difficult, if not impossible, to remember all of the passwords you have. 1Password will create randomly generated passwords and store them for you. It can also enter all of your passwords for you automatically whether using your work PC, your iPhone, or your Mac at home. It now has a new payment structure that allows all devices (PC or Mac) for $\$ 36.00 /$ year. Also take a look at LastPass and Dashlane.

\section{Trello [Free - iOS, Android]}

This app allows you to have project management on the go. Track all of your current assignments and projects simply by putting them in different columns on the easy to use interface. This also can be synced with software on your desktop computer.

\section{Tripit [Free - iOS, Android]}

Simply forward all your hotel, flight, car rental, and restaurant confirmation emails to plans@tripit.com. TripIt automatically transforms your emails into a master itinerary for every trip so all your plans are in one place. It also provides maps for your destination and sends alerts for flight changes. 


\section{ScannerPro [\$3.99 - iOS]}

This app can be used to scan in documents, receipts and images. Once documents have been downloaded, they can be sent via e-mail or to Google Docs or Dropbox. If you are looking for an Android document scanner, GeniusScan \& Cam Scanner (Free - iOS, Android) are good free alternatives.

\section{Dictate + Connect [Free Version, \$16.99 iOS; \$9.99 Android]}

Using your iPhone, iPad or Android device, you can turn your mobile device into a highquality dictaphone. This app allows you to rewind, overwrite and insert and has an easyto-use interface. There are also many options to share your recordings.

\section{IFTTT [Free - iOS, Android]}

"If this then that." This app connects all of your apps you like to make them more productive. For example, you can use this app to automatically file receipts into a Google Spreadsheet, automatically put your phone on vibrate when you get to work, or get a notification when it is going to rain tomorrow. The IFTTT website has all sorts of examples you can use with this app.

\section{Doodle [Free - iOS, Android]}

Trying to schedule a meeting with multiple individuals is very difficult. Doodle is an easy solution. You suggest different times and participants are able to select their preferences. Then all participants are notified of the meeting time.

\section{Legal Productivity Apps}

Developers have seen a market in lawyers and have developed some outstanding apps specifically tailored towards attorneys. At this point, many of the apps listed below are only available on Apple devices. However, this most likely will change in the future as more developers begin to create apps for Android products. Below are the most popular legal apps that attorneys downloaded during 2017. 


\section{Most Popular Legal Apps from 2017 ABA Tech Survey}

1. Westlaw

2. Fastcase

3. LexisAdvance

4. Legal Dictionary (generic term)

5. TrialPad

6. TranscriptPad

7. Courtlink

8. LexisNexis Legal News

9. LexisNexis Get Cases \& Shepardize

10. HeinOnline

11. Westlaw News

\section{Courtroom Apps}

\section{TrialPad [\$129.99 - iOS]}

This app was specifically designed for attorneys to use their iPad in the courtroom. TrialPad allows attorneys to organize, manage, annotate, and store their documents and videos in their iPad. Attorneys can then display the documents in "presentation view" which will show the content on the entire screen and transition between the documents like a PowerPoint presentation. This app is consistently the leader in trial preparation apps.

\section{Jury Selection Apps}

\section{iJuror [\$14.99 - iOS, Android]}

This iPad app was created for attorneys during jury selection and is currently the most popular jury app available. This app lets the attorney add juror information based upon where a juror is sitting, add notes as the trial proceeds, and has drag and drop features to select and drop jurors. It also allows you to keep statistics on the various juries that an attorney encounters. 


\section{Time Tracking Apps}

\section{iTimekeep [iOS, Android, Windows]}

This time tracking app has been designed to integrate with most billing and mattermanagement software used by law firms. If your firm uses any popular billing software packages this app will most likely connect seamlessly with it. This has received raving reviews by lawyers but has some costs associated with it.

\section{Time Master+Billing [\$9.99 - iOS, Android]}

While this app is not designed specifically for lawyers, it has been reviewed favorably by lawyers to be an inexpensive, easy-to-use app for tracking billable time while away from the office.

\section{Other Legal Productivity Apps}

\section{CaseManager [\$44.99, iOS, Android]}

This app was designed for solo practitioners and small firms to organize their law practice. This app allows you to store all of the key information about your case: pleadings, documents, notes, contact information, etc. This app is not designed to compete with the expensive case management software but it is a good, simple alternative for small firms.

\section{AgileLaw [Free (requires account) - iOS]}

Allows you to upload, annotate and organize exhibits to be used at trial or a deposition. This app permits multiple attorneys to access the exhibits from anywhere.

\section{TranscriptPad [\$89.99, iOS]}

As the name suggests, this iPad app assists attorneys in reviewing transcripts. TranscriptPad lets attorneys code issues, search text, prepare reports and organize transcripts. Once the transcripts are uploaded into this app, it automatically will fill in information about the deponents, dates, case number and other identifying information. 


\section{DocReviewPad [\$89.99, iOS]}

This app transforms your iPad into a document review machine. It allows you to assign bates numbering and assign built-in tags for confidential, privileged, responsive or relevant. You can also create your own tags or issue codes and annotate the documents.

\section{Cite-Checker [\$2.99 - iOS, Android]}

While this app was probably designed with law students in mind, this app provides the Bluebook rules in an easy to understand manner. It has explanations and examples for statutes and cases at the federal and state level.

\section{Legal Research Apps}

These apps are designed to let you research legal issues while away from the office. Some of these are through fee based subscriptions like Westlaw and Lexis. However, there are many free apps that provide access to primary laws. The good news is that most of these apps are available for both Android and Apple devices.

\section{FastCase [Free - iOS, Android]}

As members of the Georgia Bar you are familiar with FastCase. This legal research database, which is free to Georgia Bar members, has developed an app so that you can use this database on your mobile device. This app has won many awards for its intuitive design and interface. This app will allow lawyers to locate statutes and cases from while away from the office.

\section{Westlaw [Free (for subscribers) - iOS, Android]}

For those of you that subscribe to Westlaw, there is a free app that allows you to use this legal database wherever you go. The research you perform on your mobile device is fully synchronized with your account, so when you get back to your office the research will be up to date on your office computer. This allows researchers to search cases, statutes, regulations and even treatises that are within their subscription. 


\section{LexisAdvance [Free (for subscribers) - iOS]}

J ust like Westlaw, LexisNexis has developed a free app for its next generation database, LexisAdvance. For subscribers of LexisAdvance, this app allows researchers to search for applicable cases, statues, regulations and treatises that are within their subscription.

\section{Bloomberg Law [Free (for subscribers) - iOS, Android]}

Bloomberg Law has quickly become a competitor to Lexis and Westlaw. It has also issued a new app that allows you to research all of Bloomberg Law including its BNA materials.

\section{HeinOnline [Free (for subscribers), iOS, Android]}

HeinOnline gives users access to a wide variety of legal materials including journals, statutes, and treatises. University of Georgia Law Alumni now have free access to the Law Journal Library through the Law School's Alumni Portal at: https:// www.law.uga.edu/cgi-bin/ alumni/portal/ home.pl

\section{Law Stack [Free - iOS]}

Law Stack describes its app as "a legal library in your pocket." It contains the Constitution, Federal Rules of Civil Procedure, Federal Rules of Appellate Procedure, Federal Rules of Evidence, Federal Rules of Bankruptcy Procedure, and Federal Rules of Criminal Procedure. DroidLaw is a great alternative for Android users.

\section{Courtroom Objections [\$2.99 - iOS]}

This app provides lists of common objections and responses. The app organizes the potential objections into various categories and has an easy-to-use interface.

\section{Wolfram Lawyer's Professional Assistant [\$4.99 - iOS]}

This is a nice reference tool for busy attorneys. This app contains detailed reference information and data in major legal fields. It is a good first stop for quick lookups and fact checking. Features include - statutes of limitations, current interest rates, calendar computations and much more. 


\section{Miscellaneous Apps}

\section{FindmyiPhone [Free - iOS]; Android Device Manager [Free - Android]}

These are essential apps for any mobile device user. These apps allow owners of smartphones and tablets to logon to a computer and locate the specific location of their devices if they are ever misplaced or stolen. These apps also allow owners to remotely lock the device or remove data from it in the event that it is lost. You never know how valuable these apps are until you cannot find your phone or tablet.

\section{Crackle [Free - iOS, Android]}

This is one of the few apps that lets individuals watch movies and television shows free. There are over 200 movies to choose from and it also includes popular old television shows and original series. Please note that this app requires a wi-fi connection.

\section{Tunity [Free - iOS, Android]}

If you are at an airport or a restaurant and want to hear a television when it is muted, then Tunity is your answer. J ust point your camera at the TV and the app will locate the audio for the TV program.

\section{NPR One [Free - iOS, Android]}

This recently updated app is a great way to listen to NPR anywhere. It can also be configured to your local station so you can continue to hear local news while you are away from home.

\section{Streaks [\$4.99 - iOS]}

Have a NewYear's resolution? This app will keep you on task. This app tracks your habits and records when you achieve (or miss) a goal.

\section{Whitenoise [Free - iOS, Android]}

Having trouble falling asleep? This app plays rain, airplane engines, waves, fans, and other noises to help you fall asleep. 